\title{
Characterization and in vitro properties of Lactobacillus plantarum and Leuconostoc mesenteroides for probiotic potential and nitrite degradation
}

\author{
Jiang Jikang ${ }^{\mathrm{a}}$, Li Wenxiang ${ }^{\mathrm{b}, *}$ \\ ${ }^{a}$ Qingdao Agricultural University, Qingdao, China \\ b Shandong Provincial Laboratory of Applied Mycology, Qingdao Agricultural University, Qingdao, China
}

*Corresponding author, e-mail: xiang7332@126.com

Received 25 Jul 2019

Accepted 23 Nov 2019

\begin{abstract}
In the present work, the nitrite degradation activity and probiotic potential of heterofermentative Leuconostoc mesenteroides (LM) and homofermentative Lactobacillus plantarum (LP) were demonstrated. The potential probiotic properties of these bacteria were determined in vitro based on their antimicrobial activity, antibiotic resistance, aggregation properties, hydrophobicity, survival under simulated gastrointestinal tract conditions, and hemolytic activity. The results suggested that these two lactic acid bacteria (LAB) species possess hydrophobicity as they exhibited microbial adhesion to xylene, chloroform, and ethyl acetate. The two strains also showed general resistance to simulated gastric and intestinal conditions. The LM was resistant to erythromycin, chloramphenicol, norfloxacin, and vancomycin, while the LP showed resistance to clindamycin, tetracycline, erythromycin, norfloxacin, and vancomycin. Both LAB were efficient antimicrobials toward Escherichia coli and Staphylococcus aureus based on their inhibition zones. Furthermore, these LAB showed good tolerance toward nitrite, and displayed $\alpha$ - and $\gamma$-hemolysis. These results suggest that LM and LP are promising probiotic candidates.
\end{abstract}

KEYWORDS: probiotics, gastro-intestinal resistance, antibiotic susceptibility, nitrite degradation

\section{INTRODUCTION}

Probiotics are generally defined as a live microorganisms which, when administered in adequate amounts confer a health benefit on the host ${ }^{1}$. LAB, one of the known probiotic microorganisms, have a widely use in various fermented products, such as pickles, bean paste, natto, miso, jiaosu. These microbial groups possess many host-associated functions including anti-cholesterol activity, anti-oxidant activity and so on ${ }^{2-4}$. Currently, LAB strains possessing various functions are applied in the global commercial production of probiotic fermented foods, but demand remains for further bio-functional products as well as increased implementation and diversification ${ }^{5}$. Therefore, it is necessary to select new strains with certain functional properties to respond to the emerging consumer demand.

$\mathrm{LAB}$ is divided into heterofermentative strains and homofermentative strains according to the type of fermentation they employ. Among these, heterofermentative LAB such as L. mesenteroides, which mainly produce $\mathrm{CO}_{2}$, organic acid, and flavor substances as metabolic products, are only predomi- nant during the early stages of fermentation and are responsible for the high sensory quality of fermented products ${ }^{6}$. The subsequent stages of fermentation are dominated by homofermentative LAB such as $L$. plantarum, which produces mostly acids. Fermentation can be controlled to improve product quality and prolong the product shelf life with the help of these two different types of LAB (homofermentative and heterofermentative). In recent studies ${ }^{7-9}$, the dominance of Lactobacillus and Leuconostoc spp. during enset fermentation was reported and these LAB are likely important because they can contribute to the sensory characteristics and preservative effects ${ }^{10}$. It is reported that the main benefits of using microorganisms in fermented products are: (1) extending shelf life; (2) improve nutritional value; (3) enhance organoleptic food quality; and (4) improve food safety by inhibiting pathogens or by decomposing toxic compounds such as nitrite ${ }^{11}$.

Nitrite is the precursor of N-nitroso compounds. As we know, the augment of nitrite content is an unavoidable problem during vegetable fermentation ${ }^{12}$. Nitrite may be involved in N-nitrosamine 
formation by $\mathrm{N}$-nitrosation reactions with dietaryderived amines in the stomach ${ }^{13}$. It is reported that nitrite leads to potential risks of suffering from some diseases such as methemoglobinemia and gastric cancer by long-term ingestion of food containing nitrite ${ }^{14}$. Kim et $\mathrm{al}^{15,16}$ reported that the $\mathrm{N}$ nitrosodimethylamine levels produced by LAB can be reduced by decreasing the level of precursors such as nitrite and biogenic amines, as well as through direct depletion or degradation of nitrite in De Man, Rogosa, and Sharpe (MRS) broth containing N-nitrosodimethylamine or $\mathrm{NaNO}_{2}$, respectively. Thus, LAB has been one of the efficient strategies to degrade nitrite.

The objective of the current study was to investigate the probiotic potential of these two strains and properties of nitrite degradation in order to be used as starter culture.

\section{MATERIALS AND METHODS}

\section{Bacterial cultures and media}

L. mesenteroides (LM) and L. plantarum (LP) from Qingdao Agricultural University were grown in MRS broth (Beijing Land Bridge Technology Co., Ltd.) at $30^{\circ} \mathrm{C}$ for $24 \mathrm{~h}$ and pathogenic bacteria (E. coli CICC 24189 and S. aureus CICC 10384) were cultured in nutrient broth (Beijing Solarbio Science \& Technology Co., Ltd) at $37^{\circ} \mathrm{C}$ for $24 \mathrm{~h}$.

\section{Antagonistic activities}

Antagonistic activities against pathogens (E. coli and $S$. aureus) were tested by the agar-well diffusion method ${ }^{17}$. Briefly, the LABs were collected by centrifugation $\left(2107 \times \mathrm{g}, 10 \mathrm{~min}, 4^{\circ} \mathrm{C}\right)$ and then filtered by $0.22 \mu \mathrm{m}$ filter membrane to obtain cellfree supernatant (CFS). The pathogens were grown in nutrient broth at $37^{\circ} \mathrm{C}$ for $24 \mathrm{~h}$. The concentration of the pathogens was adjusted to approximately $106 \mathrm{CFU} / \mathrm{ml}$ and then incorporated into LB medium (Beijing Land Bridge Technology CO., Ltd.). Each CFS was transferred into Oxford cup which was put on the surface of the agar, respectively. After incubated at $37^{\circ} \mathrm{C}$ for $24 \mathrm{~h}$, the diameter of the inhibition zone was measured. Both LABs against E. coli CICC 24189 , S. aureus CICC 10384 were performed in duplicate.

\section{Antibiotic resistance}

Antibiotic resistance for $\mathrm{LAB}$ was determined as described previously ${ }^{18,19}$. Exactly, the following 8 antimicrobial agents (Shanghai Ryon Biological Technology Co., Ltd) were used: ampicillin, chloram- phenicol, streptomycin, tetracycline, erythromycin, clindamycin, norfloxacin, and vancomycin. Antibiotics were diluted serially in appropriate differently diluents. The antibiotics in MRS broth were adjusted, ranging from 0.5 to $1024 \mu \mathrm{g} / \mathrm{ml}$ with two times concentration gradient. MRS broth containing different concentrations of antibiotics was added into each well. The LAB strains grown overnight at $37^{\circ} \mathrm{C}$ were approximately diluted to 0.6 at OD600, equivalent to the McFarland standard 0.5, and then prepared to each well of the microtiter plates. After incubation for $24 \mathrm{~h}$ at $37^{\circ} \mathrm{C}$, minimal inhibitory concentration (MIC) was obtained in triplicate in accordance with OD600.

\section{Tolerance to simulated gastric and intestinal conditions}

All methods were based on those described previously ${ }^{19}$ with a slight modification. Simulated gastric condition was prepared by suspending $3 \mathrm{~g} / 1$ pepsin (Shanghai Aladdin Bio-Chem Technology Co., Ltd) in a sterile $0.5 \% \mathrm{NaCl}(\mathrm{w} / \mathrm{v})$ solution. $1 \mathrm{M} \mathrm{HCl}$ was used to adjust to $\mathrm{pH} 3.5 .1 \mathrm{~g} / \mathrm{l}$ pancreatin (Shanghai Aladdin Bio-Chem Technology Co., Ltd) and 0.15 or $0.3 \%$ bile salts (Shanghai Aladdin BioChem Technology Co., Ltd, w/v) were suspended in a sterile $0.5 \% \mathrm{NaCl}(\mathrm{w} / \mathrm{v})$ solution. Then $1 \mathrm{M}$ $\mathrm{NaOH}$ was used to adjust to $\mathrm{pH}$ 8.0. Then it was filtered through $0.22 \mu \mathrm{m}$ filter membrane to obtain simulated intestinal juice. Following, the overnight culture of LAB strains was harvested by centrifugation $\left(10000 \times g, 5 \mathrm{~min}, 4^{\circ} \mathrm{C}\right)$, then washed twice and resuspended in phosphate buffered saline (PBS, $\mathrm{pH}$ 7.4). Each $200 \mu \mathrm{l}$ bacterial suspension was incorporated into $1 \mathrm{ml}$ simulated gastric juice together with $300 \mu \mathrm{l}$ sterile $0.5 \% \mathrm{NaCl}(\mathrm{w} / \mathrm{v})$ solution. The mixture was cultured for $120 \mathrm{~min}$ at $37^{\circ} \mathrm{C}$. Then, survivor cells from gastric juice were harvested by centrifugation $\left(6000 \times \mathrm{g}, 5 \mathrm{~min}, 4^{\circ} \mathrm{C}\right)$, then washed twice and resuspended in phosphate buffered saline (PBS, pH 7.4). Similarly, each $200 \mu l$ bacterial suspension was incorporated into $1 \mathrm{ml}$ simulated intestinal juice together with $300 \mu \mathrm{l}$ sterile $0.5 \%$ $\mathrm{NaCl}(\mathrm{w} / \mathrm{v})$ solution. The mixture was cultured for $120 \mathrm{~min}$ at $37^{\circ} \mathrm{C}$. Viable counts were determined by plating a serial dilution on MRS agar plates.

\section{Aggregation property}

Autoaggregation and coaggregation assays were performed according to Zuo et $\mathrm{al}^{20}$. The overnight culture of LAB was harvested by centrifugation $(6000 \times g, 10 \mathrm{~min})$, then washed twice and resuspended in PBS and adjusted OD600 $=1.0$. And 
$0.1 \mathrm{ml}$ of upper suspension was mixed with $1.9 \mathrm{ml}$ PBS and OD600 was measured after incubation at $37^{\circ} \mathrm{C}$ for $2 \mathrm{~h}$. Percent autoaggregation was expressed as 1- (OD600 of upper suspension/OD600 of total bacterial suspension) $\times 100$.

Bacterial suspensions were prepared as described above. LAB bacterial suspensions $(1 \mathrm{ml})$ were mixed with $1 \mathrm{ml} E$. coli CICC 24189 bacterial suspensions and OD600 was determined immediately (designated $\mathrm{A}_{0}$ ). After incubation at $37^{\circ} \mathrm{C}$ for $2 \mathrm{~h}$, OD600 was determined again (designated as $A_{t}$ ). Percent co-aggregation was expressed as $\left(\mathrm{A}_{0}-\mathrm{A}_{\mathrm{t}}\right) / \mathrm{A}_{0} \times 100$.

\section{Bacterial adhesion to hydrocarbons}

The cell surface hydrophobicity test was measured based on the previous work ${ }^{21}$.

\section{Hemolytic activity}

Fresh LABs were streaked on Columbia agar plates, containing 5\% (w/v) human blood (Michopoulos S.A., Athens, Greece), and incubated for $48 \mathrm{~h}$ at $30^{\circ} \mathrm{C}$ according to preceding study ${ }^{22}$.

\section{Tolerance capability on nitrite}

The tolerance capability on nitrite assays were determined with the $\mathrm{N}$ - (1-naphthyl)-ethylenediamine dihydrochloride spectrophotometric method in the light of previous study ${ }^{23}$. Percent degradation was expressed as $\left(\mathrm{OD}_{\mathrm{i}}-\mathrm{OD}_{\mathrm{t}}\right) / \mathrm{OD}_{\mathrm{i}} \times 100$, where $\mathrm{OD}_{\mathrm{t}}$ represents absorbance at time $t$ and $\mathrm{OD}_{\mathrm{i}}\left(\mathrm{OD}_{0.2}\right.$, $\left.\mathrm{OD}_{0.4}, \mathrm{OD}_{0.6}, \mathrm{OD}_{0.8}, \mathrm{OD}_{1.0}\right)$ represents absorbance at $0.2,0.4,0.6,0.8,1.0 \mathrm{mg} / \mathrm{ml}$ nitrite.

\section{Statistical analysis}

All experiments were performed in triplicate. The results are presented as mean $\pm \mathrm{SD}$. The data of tolerance capability on nitrite was performed using ORIGINPRo 9.1 software (OriginLab Corp., US).

\section{RESULTS}

\section{Antagonistic activities and antibiotic resistance}

In this study, two LABs were tested for antimicrobial activity toward $E$. coli and $S$. aureus. As indicated in Table 1, the CFS of the selected LABs expressed a clear inhibition zone (LM, 1.74 and $2.60 \mathrm{~mm}$; LP, 1.65 and $2.65 \mathrm{~mm}$ ) against the two indicators, respectively.

$\mathrm{LAB}$ is considered to be antibiotic-resistant when it shows a MIC value higher than the MIC breakpoints established by the European Food
Safety Authority (EFSA). As shown in Table 1, neither of the LAB revealed sensitivity toward ampicillin or streptomycin. However, the LM was resistant toward erythromycin, chloramphenicol, norfloxacin, and vancomycin, while the LP showed resistance toward clindamycin, tetracycline, erythromycin, norfloxacin, and vancomycin.

\section{Tolerance to simulated gastrointestinal conditions}

Probiotics can be used to restore microbial homeostasis in the gut. Important criteria for the selection of probiotics are that following ingestion, they must maintain cellular integrity and they must retain their beneficial metabolic functions ${ }^{24}$. During passage through the gastrointestinal tract, probiotic cells face hostile, antimicrobial conditions, namely low $\mathrm{pH}$ and the presence of bile salts, pepsin or pancreatin. Here, we tested the tolerance of the two LABs toward simulated gastric and intestinal conditions (Table 2). The secretion resembling gastric juice had a profound effect on the viability of the LAB. The survival rate of the strains in the simulated gastric conditions varied from more than $6-18 \%$ over a period of $2 \mathrm{~h}$. The physiological concentration of human bile ranges from $0.1-0.3 \%$, and the survival rate of the LABs under simulated intestinal conditions with $0.15 \%$ and $0.3 \%$ bile salts varied from $0.6 \pm 0.7 \%$ to $11.4 \pm 0.7 \%$ after $2 \mathrm{~h}$ (Table 2 ). The low survival of the two selected LABs under these conditions may be related to the bile salts' capacity to alter the structure of cell membranes, which is toxic to bacterial cells ${ }^{25}$.

\section{Autoaggregation and hydrophobicity}

In this study, the cell surface properties of autoaggregation and hydrophobicity were tested. The two selected LAB strains exhibited high autoaggregation after incubation for $2 \mathrm{~h}$ at $37^{\circ} \mathrm{C}$ (Table 3). High autoaggregation contributes toward LAB strains reaching a high density in gastrointestinal tract, enabling their plentiful biological functions such as anticholesterol and anti-oxidant activity ${ }^{2-4}$.

Cell surface hydrophobicity methods were mainly measured the bacterial adhesion to a certain hydrophobic substratum rather than intrinsic microbial cell surface hydrophobicity ${ }^{26}$. In this work, xylene, chloroform and ethyl acetate were used as hydrophobic substratum. The bacterial adhesion to chloroform and ethyl acetate were regarded as a measure of electron donor/basic and electron acceptor/acidic characteristics of bacterial surface, respectively ${ }^{27}$. As shown in Table 4, both strains 
Table 1 Antimicrobial activity and antibiotic resistance of the LAB.

\begin{tabular}{|c|c|c|c|c|c|c|c|c|c|c|}
\hline \multirow{2}{*}{ LAB } & \multicolumn{8}{|c|}{ MIC $(\mu \mathrm{g} / \mathrm{ml})$} & \multicolumn{2}{|c|}{ Inhibitory zone $(\mathrm{cm})$} \\
\hline & A & CL & S & $\mathrm{T}$ & $\mathrm{E}$ & C & $\mathrm{N}$ & V & E. coli & S. aureus \\
\hline L. mesenteroides & 1 & 1 & 128 & 32 & $4^{\mathrm{R}}$ & $16^{\mathrm{R}}$ & $16^{\mathrm{R}}$ & $>1024$ & 1.74 & 2.60 \\
\hline L. plantarum & 1 & $2^{\mathrm{R}}$ & 64 & $32^{\mathrm{R}}$ & $2^{\mathrm{R}}$ & 4 & $16^{\mathrm{R}}$ & $>1024$ & 1.65 & 2.65 \\
\hline
\end{tabular}

${ }^{\mathrm{R}}$ Antibiotic resistance according to EFSA's breakpoints (EFSA, 2008). A, ampicillin; C, chloramphenicol; S, streptomycin; T, tetracycline; E, erythromycin; CL, clindamycin; N, norfloxacin; V, vancomycin.

Table 2 Effect of simulated gastric juice and simulated intestinal juice on the viable counts of the LAB at different incubation times.

\begin{tabular}{lccrr}
\hline \multirow{2}{*}{$\mathrm{LAB}$} & \multicolumn{2}{c}{ Gastric } & $\mathrm{SC}^{\dagger}$ & Intestinal \\
\cline { 2 - 3 } & $60 \mathrm{~min}$ & $120 \mathrm{~min}$ & $(\%)$ & $120 \mathrm{~min}$ \\
\hline L. mesenteroides & $13.5 \pm 2.4$ & $6.3 \pm 0.8$ & 0.15 & $1.0 \pm 0.9$ \\
& & & 0.30 & $0.6 \pm 0.7$ \\
L. plantarum & $18.3 \pm 6.2$ & $12.5 \pm 5.1$ & 0.15 & $11.4 \pm 0.7$ \\
& & & 0.30 & $7.6 \pm 0.7$ \\
\hline
\end{tabular}

$\dagger$ SC, \% survival concentration of bile salts.

Results are shown as average percentages of survived bacteria (\%) \pm SD.

Table 3 Autoaggregation and coaggregation activities of the LAB.

\begin{tabular}{lccc}
\hline \multirow{2}{*}{ LAB } & Autoaggregation & \multicolumn{2}{c}{ Coaggregation } \\
\cline { 2 - 4 } & $2 \mathrm{~h}$ & $2 \mathrm{~h}$ & $24 \mathrm{~h}$ \\
\hline L. mesenteroides & $78.78 \pm 2.53$ & $24.24 \pm 0.30$ & $44.67 \pm 1.74$ \\
L. plantarum & $76.65 \pm 0.23$ & $19.19 \pm 0.51$ & $45.72 \pm 5.19$ \\
\hline
\end{tabular}

Results are shown as average percentages $(\%) \pm$ SD.

showed high affinity toward all three of the solvents used in this study, ranging from $76.94 \pm 2.10 \%$ to $94.89 \pm 0.76 \%$.

\section{Coaggregation and hemolytic activity}

The coaggregation ratios between the LABs and E. coli are also shown in Table 3. As expected, the percentage of coaggregation increased with time over the $24 \mathrm{~h}$ tested. The coaggregation of the LM and LP with E. coli was $44.67 \pm 1.74 \%$ and $45.72 \pm 5.19 \%$, respectively, after $24 \mathrm{~h}$.

Hemolytic activity is commonly assayed to as-

Table 4 Hydrophobicity and hemolytic activity of the LAB.

\begin{tabular}{lcccc}
\hline LAB & Xylene & Chloroform & Ethyl acetate & HA \\
\hline L. mesenteroides & $85.03 \pm 1.44$ & $76.94 \pm 2.10$ & $87.94 \pm 0.21$ & $\alpha$ \\
L. plantarum & $94.89 \pm 0.76$ & $91.33 \pm 0.07$ & $93.35 \pm 2.18$ & $\gamma$ \\
\hline$\dagger$ & & \\
\multicolumn{4}{l}{ HA, hemolytic activity. } \\
\multicolumn{4}{l}{ Results are shown as average percentages (\%) \pm SD. }
\end{tabular}

sess the safety of probiotic bacteria ${ }^{5}$. As displayed in Table 4, the two strains showed $\alpha$ - and $\gamma$-hemolysis when grown in Columbia blood agar. Neither of the examined strains exhibited $\beta$-hemolytic activity when grown in Columbia blood agar.

\section{Tolerance toward nitrite}

The tolerance of the two strains toward nitrite is displayed in Fig. 1. As shown in Fig. 1a, the nitrite depletion rate of LM was maintained above $70 \%$ after $48 \mathrm{~h}$ when the nitrite concentration was $0.2 \mathrm{mg} / \mathrm{ml}$. Notably, the LP strain exhibited good levels of nitrite degradation of above $70 \%$ after $24 \mathrm{~h}$ (Fig. 1b).

\section{DISCUSSION}

When probiotics are applied to the gastrointestinal tract, they produce miscellaneous components that can kill pathogens, enhance epithelial barrier function, and modulate immune responses ${ }^{28}$. In addition, $\mathrm{LAB}$ are used to improve the safety and shelf-life of minimally processed foods such as sliced apples and lamb's lettuce ${ }^{29}$. Therefore, the antagonistic activity of the probiotic candidate toward specific microbes is extremely important. The two selected LAB exhibited obvious antimicrobial activity, and this activity may be related to the production of hydrogen peroxide or organic acids such as lactic acid. Several researchers ${ }^{30}$ have confirmed the effect of the antimicrobial activity of organic acids on Gram-positive and Gram-negative pathogenic bacteria. This antimicrobial activity is probably also related to bacteriocins produced by LAB. Several studies ${ }^{31}$ have reported that bacteriocin combined with physicochemical treatments with reagents, such as organic acids or phenolic compounds, could strengthen antimicrobial activity toward Gram-negative bacteria.

Microbial cell autoaggregation ability ensures that the probiotic reaches a high cell density in the gut. Coaggregation with a potential pathogen allows the probiotic strain to inhibit effectively the 

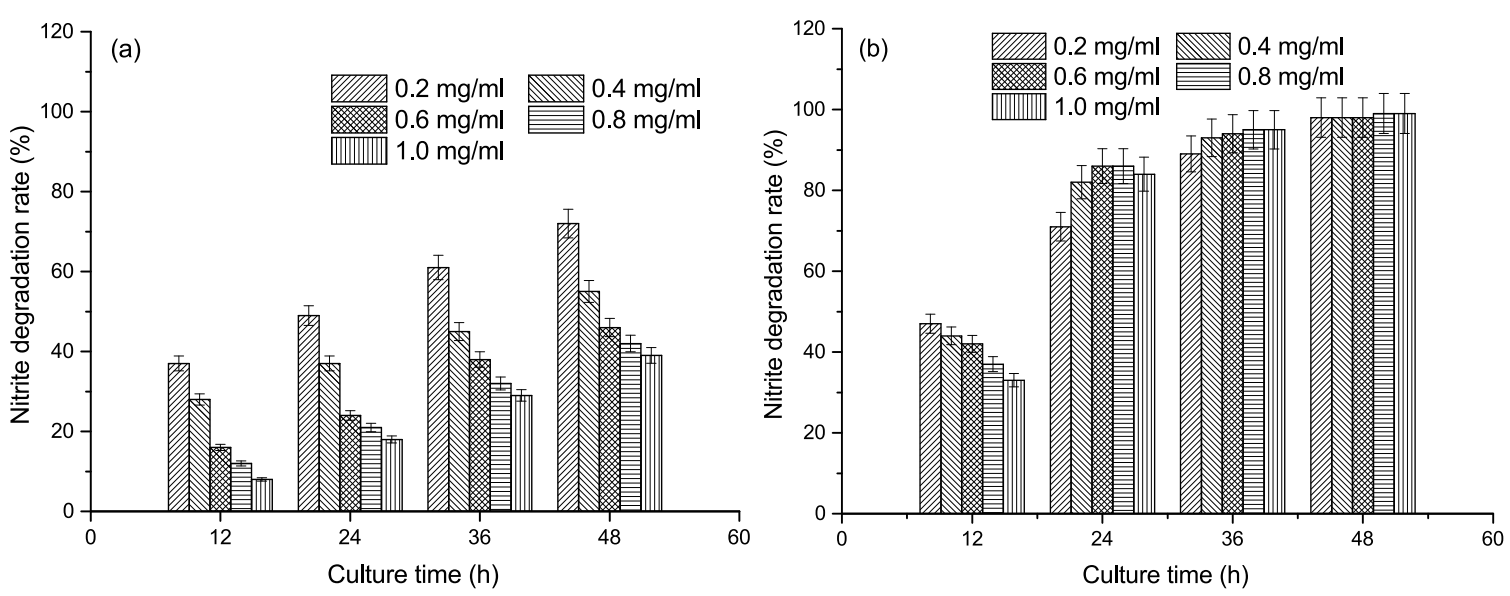

Fig. 1 Tolerance capability of (a) L. mesenteroides and (b) L. plantarum on nitrite in MRS broth.

growth of pathogenic strains and facilitate its elimination through feces in the gastrointestinal tract. Recently, it was demonstrated that aggregation of probiotic strain effectively produced antimicrobial substances ${ }^{32}$, suggesting that autoaggregation and coaggregation are closely associated with the antagonistic effect of LAB.

The absence of hemolytic activity is considered a safety prerequisite for the selection of probiotic strains. It is known that some bacterial species produce hemolysin, which can damage human red blood cells. Hemolysin activity produces a halo around bacterial colonies when cultured on media supplemented with blood. Based on this, hemolytic activity can be divided into $\alpha$-hemolytic (green halo) as a result of the production of hemoglobin, $\beta$ hemolytic (transparent to opaque halos of 2-4 mm) caused by complete hemolysis of red blood cells, or $\gamma$-hemolytic (no halo) due to the absence of any hemolytic activity. In this study, both strains showed $\alpha$-hemolysis and $\gamma$-hemolysis, indicating safety for food application.

The fact that a high percentage of LM and LP cells adhered to xylene, chloroform and ethyl acetate, demonstrated hydrophobic cell surface of this strain. Many previous studies on the physicochemistry of microbial cell surfaces have shown that the presence of (glyco-) proteinaceous material at the cell surface results in higher hydrophobicity, whereas hydrophilic surfaces are associated with the presence of polysaccharides ${ }^{33}$. It is known that only pronase- and pepsin-sensitive surface molecules are responsible for cell surface hydrophobicity in bacteria. Hydrophobic cell surface structure of two strains is also to be further studied ${ }^{33}$.

The antibiotic resistance mechanisms of bac- terial strains include reduced antibiotic intake, increased antibiotic elimination, modifications of the target site of antibiotics, and hydrolysis or modification of the antibiotics ${ }^{34}$. Furthermore, Antibiotic resistance in lactic acid bacteria is mainly distinct from intrinsic and acquired resistance. Intrinsic resistance is an inherent characteristic; for example, $L$. mesenteroides and $L$. plantarum are characterized as having intrinsic resistance to vancomycin, which is not transferable to other species and strains ${ }^{35}$. The reason for the LAB in the present work being resistant to vancomycin may be the result of the replacement with D-Ala-D-lactate instead of the normal D-Ala-D-Ala cell wall precursor, which is the target of the antibiotic ${ }^{36}$. However, the intrinsic resistance of LAB toward antibiotics is not considered a risk to animal and human health ${ }^{37}$. LAB use in this work, antibiotic resistance is probably caused by antibiotic resistance genes or drug efflux mechanisms or even gene mutations, with the two strains showing resistance to erythromycin, chloramphenicol, norfloxacin/erythromycin, norfloxacin, tetracycline, and clindamycin. Furthermore, for some genera of lactic acid bacteria, there are no generally accepted standard procedures for MIC determination and information on MIC ranges is rather limited. It is matter of debate whether $\mathrm{LAB}$ considering generally regarded as safe should be resistant or sensitive against antibiotics. What's more, resistance of the probiotic to some antibiotics could be used for both preventive and therapeutic purposes in controlling intestinal infections ${ }^{21}$. Therefore, further reason is also to be studied.

Nitrite intake is a serious human health problem that should not be ignored. Nitrite intake in the human diet mainly comes from vegetables but nitrite 
can be depleted through the fermentation of pickled vegetable products. Notably, nitrite content tends to vary over a wide range. For example, it was reported that 218 samples of pickled vegetables in northeast China had nitrite content ${ }^{38}$ ranging from 0.01$42.03 \mathrm{mg} / \mathrm{kg}$. Researchers ${ }^{39}$ have used L. pentosus as a starter culture to ferment oyster mushrooms, and their results suggested a nitrite content ranging from $1.85 \pm 0.71$ to $5.69 \pm 0.58 \mathrm{mg} / \mathrm{kg}$. Therefore, it is necessary to investigate the tolerance of probiotic toward nitrite. In the present study, the LP strain exhibited higher nitrite degradation than the LM strain. This may be related to differences in $\mathrm{pH}$ and enzymes. Nitrite degradation can occur via nitrite reductase degradation or acid degradation, with the latter being more efficient ${ }^{40}$. L. mesenteroides mainly produces $\mathrm{CO}_{2}$, organic acid, and flavor substances as metabolic products, is predominantly active during the early stages of fermentation, and is responsible for the high sensory quality of fermented products. L. plantarum, in contrast, produces mostly acids; therefore, L. plantarum exhibits higher nitrite degradation levels than L. mesenteroides.

\section{CONCLUSION}

In the present study, probiotic potential of two different LAB, namely L. mesenteroides and L. plantarum was demonstrated. Both strains exhibited high properties based on antimicrobial activity, antibiotic resistance, aggregation, hydrophobicity and hemolytic activity. Meanwhile, we also investigated the tolerance toward nitrite for both strains, indicating that LAB could be used to control nitrite content.

Acknowledgements: The authors would like to thank the Shandong Province Modern Agricultural Industry Technology System (SDAIT-07-07) and Shandong Province Science and Technology Development Planning Project iijĹ2014GNC113007iijL of China for supporting this research. We thank Liwen Bianji, Edanz Group China (www.liwenbianji.cn/ac), for editing the English.

\section{REFERENCES}

1. Araya M, Morelli L, Reid G, Sanders ME, Stanton C, Pineiro M, Embarek PB (2002) Guidelines for the Evaluation of Probiotics in Food, Report of a Joint FAO/WHO, London, Ontario, Canada.

2. Riaz RMS, Mehwish HM, Siddiq M, Haobin Z, Zhu J, Yan L, Shao D, Xu X, et al (2017) Identification, characterization, and probiotic potential of Lactobacillus rhamnosus isolated from human milk. LWT-Food Sci Technol 84, 271-280.

3. Amaretti A, Nunzio M, Pompei A, Raimondi S, Rossi M, Bordoni A (2013) Antioxidant properties of po- tentially probiotic bacteria: in vitro and in vivo activities. Appl Microbiol Biotechnol 97, 809-817.

4. Liong MT, Shah NP (2005) Acid and bile tolerance and cholesterol removal ability of lactobacilli strains. J Dairy Sci 88, 55-66.

5. De Melo Pereira GV, De Oliveira Coelho B, Magalhaes Junior AI, Thomaz-Soccol V, Soccol CR (2018) How to select a probiotic? A review and update of methods and criteria. Biotechnol Adv 36, 2060-2076.

6. Moon SH, Kim CR, Chang HC (2018) Heterofermentative lactic acid bacteria as a starter culture to control kimchi fermentation. LWT-Food Sci Technol 88, 181-188.

7. Andeta AF, Vandeweyer D, Woldesenbet F, Eshetu F, Hailemicael A, Woldeyes F, Crauwel S, Lievens B, et al (2018) Fermentation of enset (Ensete ventricosum) in the Gamo highlands of Ethiopia: Physicochemical and microbial community dynamics. Food Microbiol 73, 342-350.

8. Andeta AF, Vandeweyer D, Teffera EF, Woldesenbet F, Verreth C, Crauwels S, Lievens B, Vancampenhout $\mathrm{K}$, et al (2019) Effect of fermentation system on the physicochemical and microbial community dynamics during enset (Ensete ventricosum) fermentation. $J$ Appl Microbiol 126, 842-853.

9. Birmeta G, Bakeeva A, Passoth V (2019) Yeasts and bacteria associated with kocho, an Ethiopian fermented food produced from enset (Ensete ventricosum). Antonie Van Leeuwenhoek 112, 651-659.

10. Bosha A, Dalbato AL, Tana T, Mohammed W, Tesfaye B, Karlsson LM (2016) Nutritional and chemical properties of fermented food of wild and cultivated genotypes of enset (Ensete ventricosum). Food Res Int 89, 806-811.

11. Feng Y, Zhang M, Mujumdar AS, Gao Z (2017) Recent research process of fermented plant extract: A review. Trends Food Sci Tech 65, 40-48.

12. Yan PM, Xue WT, Tan SS, Zhang H, Chang XH (2008) Effect of inoculating lactic acid bacteria starter cultures on the nitrite concentration of fermenting Chinese paocai. Food Control 19, 50-55.

13. Ding Z, Johanningsmeier SD, Price R, Reynolds R, Truong VD, Payton SC, Breidt F (2018) Evaluation of nitrate and nitrite contents in pickled fruit and vegetable products. Food Control 90, 304-311.

14. Zhang ML, Huang DK, Cao Z, Liu YQ, He JL, Xiong JF, Feng ZM, Yin YL (2015) Determination of trace nitrite in pickled food with a nano-composite electrode by electrodepositing $\mathrm{ZnO}$ and $\mathrm{Pt}$ nanoparticles on MWCNTs substrate. LWT-Food Sci Technol 64, 663-670.

15. Kim SH, Kang KH, Kim SH, Lee S, Lee SH, Ha ES, Sung NJ, Kim JG, et al (2017) Lactic acid bacteria directly degrade $\mathrm{N}$-nitrosodimethylamine and increase the nitrite-scavenging ability in kimchi. Food Control 71, 101-109. 
16. Kim SH, Kim SH, Kang $\mathrm{KH}$, Lee S, Kim SJ, Kim JG, Chung MJ (2017) Kimchi probiotic bacteria contribute to reduced amounts of $\mathrm{N}$ nitrosodimethylamine in lactic acid bacteria-fortified kimchi. LWT-Food Sci Technol 84, 196-203.

17. Li W (2012) Study the pickles' technology and security in Lactobacillus preparation fermentation. $\mathrm{PhD}$ thesis, Xihua Univ, China.

18. Xu C, Li J, Yang L, Shi F, Yang L, Ye M (2017) Antibacterial activity and a membrane damage mechanism of Lachnum YM30 melanin against Vibrio parahemolyticus and Staphylococcus aureus. Food Control 73, 1445-1451.

19. Choi AR, Patra JK, Kim WJ, Kang SS (2018) Antagonistic activities and probiotic potential of lactic acid bacteria derived from a plant-based fermented food. Front Microbiol 9, ID 1963.

20. Zuo F, Yu R, Feng X, Chen L, Zeng Z, Khaskheli GB, Ma H, Chen S (2015) Characterization and in vitro properties of potential probiotic Bifidobacterium strains isolated from breast-fed infant feces. Ann Microbiol 66, 1027-1037.

21. Divya JB, Varsha KK, Nampoothiri KM (2012) Newly isolated lactic acid bacteria with probiotic features for potential application in food industry. Appl Biochem Biotechnol 167, 1314-1324.

22. Maragkoudakis PA, Zoumpopoulou G, Miaris C, Kalantzopoulos G, Pot B, Tsakalidou E (2006) Probiotic potential of Lactobacillus strains isolated from dairy products. Int Dairy J 16, 189-199.

23. Xia Y, Liu X, Wang G, Zhang H, Xiong Z, Sun Y, Ai L (2017) Characterization and selection of Lactobacillus brevis starter for nitrite degradation of Chinese pickle. Food Control 78, 126-131.

24. Amorim JC, Piccoli RH, Duarte WF (2018) Probiotic potential of yeasts isolated from pineapple and their use in the elaboration of potentially functional fermented beverages. Food Res Int 107, 518-527.

25. Vitola H, Dannenberg G, Marques J, Lopes G, Silva W, Fiorentini A (2018) Probiotic potential of Lactobacillus casei CSL3 isolated from bovine colostrum silage and its viability capacity immobilized in soybean. Proc Biochem 75, 22-30.

26. Del Re B, Sgorbati B, Miglioli M, Palenzona D (2000) Adhesion, autoaggregation and hydrophobicity of 13 strains of Bifidobacterium longum. Lett Appl Microbiol 31, 438-442.

27. Martin R, Olivares M, Marin ML, Fernandez L, Xaus J, Rodriguez JM (2005) Probiotic potential of 3 Lactobacilli strains isolated from breast milk. J Hum Lact 21, 8-17.

28. Lebeer S, Vanderleyden J, De Keersmaecker SC
(2008) Genes and molecules of lactobacilli supporting probiotic action. Microbiol Mol Biol Rev 72, 728-764.

29. Siroli L, Patrignani F, Serrazanetti DI, Tabanelli G, Montanari C, Gardini F, Lanciotti R (2015) Lactic acid bacteria and natural antimicrobials to improve the safety and shelf-life of minimally processed sliced apples and lamb's lettuce. Food Microbiol 47, 74-84.

30. Tejero-Sarinena S, Barlow J, Costabile A, Gibson GR, Rowland I (2012) In vitro evaluation of the antimicrobial activity of a range of probiotics against pathogens: evidence for the effects of organic acids. Anaerobe 18, 530-538.

31. Alvarez-Sieiro P, Montalban-Lopez M, Mu D, Kuipers OP (2016) Bacteriocins of lactic acid bacteria: extending the family. Appl Microbiol Biotechnol 100, 2939-2951.

32. Kaewnopparat S, Dangmanee N, Kaewnopparat N, Srichana T, Chulasiri M, Settharaksa S (2013) In vitro probiotic properties of Lactobacillus fermentum SK5 isolated from vagina of a healthy woman. Anaerobe 22, 6-13.

33. Kos B, Suskovic J, Vukovic S, Simpraga M, Frece J, Matosic S (2003) Adhesion and aggregation ability of probiotic strain Lactobacillus acidophilus M92. J Appl Microbiol 94, 981-987.

34. Mathur S, Singh R (2005) Antibiotic resistance in food lactic acid bacteria: a review. Int J Food Microbiol 105, 281-295.

35. Yang P, Kong WT, Sun ZL, XU Y, Kong J (2014) Safety assessment of lactic acid bacteria isolated from foods and drugs. Food Sci 35(19), 169-173. [in Chinese]

36. Caggia C, De Angelis M, Pitino I, Pino A, Randazzo CL (2015) Probiotic features of Lactobacillus strains isolated from Ragusano and Pecorino Siciliano cheeses. Food Microbiol 50, 109-117.

37. Al Kassaa I, Hamze M, Hober D, Chihib NE, Drider D (2014) Identification of vaginal lactobacilli with potential probiotic properties isolated from women in North Lebanon. Micro Ecol 67, 722-734.

38. Hou JC, Jiang CG, Long ZC (2013) Nitrite level of pickled vegetables in Northeast China. Food Control 29, 7-10.

39. Liu Y, Xie XX, Ibrahim SA, Khaskheli SG, Yang H, Wang YF, Huang W (2016) Characterization of Lactobacillus pentosus as a starter culture for the fermentation of edible oyster mushrooms (Pleurotus spp.). LWT-Food Sci Technol 68, 21-26.

40. Lin H, Lin WF, Chen Z (2013) Experimental investigation and analysis on nitrite degradation by two strains of lactic acid bacteria. Food Ferment Ind 39(7), 65-68. [in Chinese] 